\title{
Vineyard Floor Management and Cluster Thinning Inconsistently Affect 'Pinot noir' Crop Load, Berry Composition, and Wine Quality
}

\author{
Alison L. Reeve \\ Department of Horticulture, Oregon State University, 4017 ALS Building, Corvallis, OR 97331 \\ Patricia A. Skinkis ${ }^{1}$ \\ Department of Horticulture, Oregon State University, 4017 ALS Building, Corvallis, OR 97331; and Oregon Wine \\ Research Institute, Oregon State University, 4017 ALS Building, Corvallis, OR 97331
}

Amanda J. Vance

Department of Horticulture, Oregon State University, 4017 ALS Building, Corvallis, OR 97331

Katherine R. McLaughlin

Department of Statistics, Oregon State University, 44 Kidder Hall, Corvallis, OR 97331

Elizabeth Tomasino

Department of Food Science and Technology, Oregon State University, 100 Wiegand Hall, Corvallis, OR 97331; and Oregon Wine Research Institute, Oregon State University, 4017 ALS Building, Corvallis, OR 97331

Jungmin Lee

U.S. Department of Agriculture-Agricultural Research Service, Horticultural Crops Research Unit (Corvallis, OR) Worksite, 29603 U of I Lane, Parma, ID 83660

Julie M. Tarara

Ste. Michelle Wine Estates, 660 Frontier Road, Prosser, WA 99350

Additional index words. Leaf area:yield, source:sink, vine balance, Vitis vinifera, yield:pruning weight, sensory

\begin{abstract}
Growers of high-end 'Pinot noir' wine grapes (Vitis vinifera L.) commonly reduce yield by cluster thinning with the goal of increasing fruit quality; however, there are no objectively defined yield targets to achieve optimum fruit composition. Canopy leaf area relative to fruit yield can affect total soluble solids (TSS), and recommendations have been established for warm wine grape production regions. However, the relationship between leaf area and photoassimilation differs among climates and training systems. Leaf area to yield (LA:Y) ratios developed in warm, arid regions may not be suitable for cool, wet regions such as western Oregon. A 3-year field study was conducted to elucidate relationships between canopy to yield ratios and berry composition for 'Pinot noir'. Vegetative growth and fruit yield were manipulated through competitive cover cropping and cluster thinning. Growth was manipulated in three ways: perennial red fescue (Festuca rubra L.) was grown in 1) both (Grass), 2) one (Alternate), or 3) neither (Tilled) of the alleyways flanking the vine row. Within each vineyard floor treatment, fruit clusters were thinned to one per shoot (Half Crop) or vines were left unthinned (Full Crop). Floor management influenced both canopy size and yield because of altered vine nitrogen $(N)$ status. Effects of crop load on berry components were not always consistent between the crop load metrics used [yield to pruning weight (Y:PW) ratio or LA:Y]. In 2 years, TSS reached a maximum at similar LA:Y; however, this did not necessarily produce optimum TSS. Yield had the greatest influence on pH and total anthocyanins (ACY) in the highest yielding, coolest year. Crop load metrics were not reliable predictors of TSS because of the dominant effect of seasonal variation. Relationships between canopy to yield metrics and other berry components were partially explained by tissue $\mathrm{N}$, photosynthetic photon flux (PPF) through the cluster zone, and/or yield. Cluster thinning to adjust yields may not alter source to sink relationships or canopy to yield ratios enough to overcome ripening limitations in cool climates. Only one wine vintage had sensory differences with Alternate-Half Crop and Alternate-Full Crop wines ranked high quality and Tilled-Half Crop and Tilled-Full Crop wines ranked low quality by both consumer and winemaker panels. Therefore, cluster thinning may have limited impact on wine sensory properties.
\end{abstract}

Viticultural literature describes crop load as a measure of canopy size relative to fruit yield and is used to assess source-sink interactions as related to vine health and berry sugar accumulation. Crop load is expressed as either Y:PW or LA:Y because leaf area is generally correlated with pruning weight. In practice, the objective is to optimize the source to sink ratio with vineyard management practices to sustain vine productivity and achieve ripeness within climatic constraints. Some studies suggest that crop load, rather than yield, may be a better indicator of wine quality (Bravdo et al., 1985; Naor et al.,
2002). Crop load metrics cannot be applied universally because source strength depends on regional and viticultural factors, such as global irradiance, temperature, canopy training, cultivar, rootstock, and inherent vine yield. Therefore, it is important to conduct research to define appropriate crop load metrics for specific regions and cultivars (Bravdo et al., 1984; Howell, 2001; Jackson and Lombard, 1993; Kliewer and Dokoozlian, 2005; Kliewer and Weaver, 1971).

Many studies have defined wine grape crop load metrics related to basic ripeness, including sugar accumulation, under greenhouse conditions (Jackson, 1986) and primarily in warm, arid regions (Geller and Kurtural, 2013; Jackson and Lombard, 1993; Keller et al., 2005; Kliewer and Weaver, 1971; Uriarte et al., 2016). However, studies that investigated relationships between crop load and wine quality have been inconclusive because of climate, cultural, and cultivar differences (Bravdo et al., 1984, 1985; King et al., 2015; Reynolds et al. 1994, 1996; Zhuang et al., 2014). Previously defined crop load metrics have not been useful for cool climate 'Pinot noir' production, in part because of limited 
applicability to the climatic or cultivar constraints.

According to what has become common viticulture theory (Howell, 2001; Jackson and Lombard, 1993; Kliewer and Dokoozlian, 2005), grapes grown in cool climates require higher LA: $\mathrm{Y}$ than those grown in warmer regions. This is based on the premise that lower daytime temperatures in cool climates restrict carbon assimilation and phenological development.

Vine size and canopy architecture affect light attenuation (Dokoozlian and Kliewer, 1995) and ultimately source-sink physiology (Reynolds and Vanden Heuvel, 2009). However, most vineyards in Oregon are trained to single canopy vertically shoot-positioned (VSP) systems, which are one of the most light-restricted training systems. Given high soil moisture and a cool climate, vines in this region are rarely water stressed and produce excess vegetative growth that requires repeated hedging to maintain the VSP canopy architecture. Repeated hedging may hinder fruit ripening, which is a negative consequence in cool climates with short growing seasons and late season rainfall that negatively affect fruit quality. This, coupled with the inherent lower yields of 'Pinot noir', may help explain why established crop load metrics are inappropriate in the current conditions (Kliewer and Dokoozlian, 2005).

To our knowledge, there is little research that shows applicability of crop load metrics for vines grown on VSP canopies under cool climate conditions. This may explain, in part, why Oregon 'Pinot noir' growers cluster-thin vineyards to a narrow range of yields across vineyards that vary in vigor and yield potential rather than strategizing yield targets relative to canopy size. Furthermore, many

Received for publication 2 Nov. 2017. Accepted for publication $18 \mathrm{Jan} .2018$.

This research project was led by principal investigator (PI) Skinkis and executed by successive graduate students Vance and Reeve. Project co-PI McLaughlin provided support for statistical analyses of viticulture and fruit composition data, and co-PI Tomasino provided expertise in sensory science design and analysis. Project co-PIs Lee and Tarara provided expertise in methodology, data interpretation, editing, and partial funding. Funds from the Northwest Center for Small Fruits Research (NCSFR), USDA-ARS CRIS (Current Research Information System) project number 2072-21000-047-00D, and the Oregon Wine Board were used, in part, to fund this project.

This publication is a portion of a dissertation by Alison L. Reeve.

We thank Rob Schultz, Bill Stoller, and others of Stoller Family Estate Vineyards (Dayton, OR) for their cooperation in conducting this on-site research and Dr. Alix Gitelman for additional statistics guidance.

Mention of trade names or commercial products in this publication is solely for the purpose of providing specific information and does not imply recommendation or endorsement by Oregon State University or the U.S. Department of Agriculture. ${ }^{1}$ Corresponding author. E-mail: patricia.skinkis@ oregonstate.edu. producers cluster-thin under the presumptive cause-effect relationship between low yields and premium wine quality (Uzes and Skinkis, 2016). To develop crop load guidelines that enhance 'Pinot noir' ripeness and fruit/wine quality in a cool climate, a 3-year study was conducted by manipulating vegetative growth and fruit yields to influence crop load. The first results of this study were published by Reeve et al. (2016). The results herein address relationships between traditional viticulture measures (yield, pruning weight, and yield to canopy metrics) and fruit composition and wine sensory perception. We hypothesized that a higher LA: $Y$ was required for Oregon 'Pinot noir' production than published elsewhere to achieve optimum ripeness, with a point of diminishing return on TSS. We also hypothesized that there would be a relationship between berry components and vine physiology or climatic factors that may explain the impacts of crop load or yield on fruit composition and wine sensory perception.

\section{Materials and Methods}

Experimental site and design. A split-plot vineyard floor management and crop level experiment was conducted from 2011 to 2013 in a commercial vineyard near Dayton, OR. The vineyard was planted in 1998 with 'Pinot noir' ( $V$. vinifera L. Dijon clone 115$)$ grafted on 101-14 rootstock at a spacing of $2.1 \mathrm{~m}$ between rows and $1.5 \mathrm{~m}$ between vines in N-S-oriented rows. Three floor management treatments served as main plots with two crop levels as subplots. The plots consisted of 16 vines in main plots and eight vines per subplot. All treatments were replicated in a completely randomized design across five field replicates. Alleyways of the entire vineyard block were seeded with red fescue ( $F$. rubra L.) in 2004 by the vineyard manager, and three different floor management practices applied in 2007 as part of an earlier study and maintained annually according to the following treatments: Grass-both alleyways flanking the vine row were not tilled and allowed to maintain growth of the perennial grass, Alternateone alleyway was maintained with grass growth, whereas the other alleyway was tilled, and Tilled - had both alleyways flanking the vine row tilled to keep free of vegetation during the entire growing season. Cultivation of alleyways was conducted with a rototiller (Rotavator HR36; Kongskilde Industries, Sorø, Denmark) in May and at least once again during midsummer to maintain alleyways free of vegetation. Crop level was adjusted through cluster thinning at the lag phase stage of berry development, $\approx 50$ $55 \mathrm{~d}$ post $50 \%$ bloom. Half of the vines in each plot were thinned to one cluster per shoot, retaining basal clusters only, and were referred to as Half Crop. The remaining vines had no clusters removed and were referred to as Full Crop. However, in both Half Crop and Full Crop treatments, the top branched section of clusters, known as "wings," was removed during the thinning pass to follow commercial standard practice. Half Crop treatments had on average $42 \%$ fewer clusters than Full Crop.

Field methods. Whole vine leaf area at véraison and yield at harvest were used to calculate the LA:Y ratio. Vine yield at harvest and dormant pruning weight postharvest were used to determine the Y:PW ratio. Whole vine leaf area, yield, and pruning weight methods and treatment means are stated in Reeve et al. (2016). No data were available for pruning weight in the 2011 season because commercial pruning occurred before field data were collected. Percent leaf blade $\mathrm{N}$ was determined at véraison, using the method described in Reeve et al. (2016) and data are reported therein. Leaf blade $\mathrm{N}$ was chosen for regression analysis with berry composition data, as leaf blades have been shown to correlate better with vine measures than petioles (Schreiner and Scagel, 2017; Schreiner et al., 2013).

The percent of ambient $P P F$ that infiltrated through the fruit zone was measured using a ceptometer (AccuPAR LP-80; Decagon Devices, Pullman, WA) positioned on the shaded side of the canopy, including the west side for morning readings and the east side for solar noon and afternoon readings. Measurements were made in the morning (1000 HR to $1050 \mathrm{HR})$, at solar noon $(1250 \mathrm{HR}$ to $1350 \mathrm{HR}$ ), and in the afternoon (1450 HR to $1600 \mathrm{HR}$ ) on $1 \mathrm{~d}$ during three berry development time points: pea size, véraison, and ripening, except in 2011 when data were only collected during the morning and solar noon at véraison. The sensor bar was held parallel to the vine row, at the height of the fruiting wire and as close to the shoots as possible, and held level in 2011 and 2013, but angled toward the sun in 2012. Above canopy $P P F$ readings were simultaneously taken with below canopy readings, but above canopy readings were averaged over the hourlong measurement period for consistency across the sampling period.

Fruit composition. Basic ripeness, including TSS, pH, titratable acidity (TA), and yeast-assimilable nitrogen (YAN), was measured using juice pressed from clusters at harvest as described in Reeve et al. (2016).

Whole-berry extracts were prepared from seven randomly selected clusters per plot that were stored at $-80{ }^{\circ} \mathrm{C}$ after harvest. The extraction process is described in Iland et al. (1996) with the following modifications. Fifty berries were collected at random from frozen destemmed berries, had their pedicels removed while the berries were still frozen, and the berries were weighed and left to defrost at room temperature $(\approx 1 \mathrm{~h})$. The berries were then pulverized using a homogenizer (IKA Ultra-Turrax T 25 digital; IKA Works, Inc., Wilmington, NC) for $45 \mathrm{~s}$ at 5806 $g_{\mathrm{n}}$ and then homogenized for another $30 \mathrm{~s}$. The homogenate $(2 \mathrm{~g})$ was weighed into $50-\mathrm{mL}$ centrifuge tubes and $15 \mathrm{~mL}$ of acidified aqueous ethanol $(0.1 \% \mathrm{HCl}, 50 \% \mathrm{v} / \mathrm{v} \mathrm{EtOH})$ was added. The mixtures were agitated on a shaker table for $1 \mathrm{~h}$ in the dark and then 
centrifuged for $10 \mathrm{~min}$ at $1800 \mathrm{~g}_{\mathrm{n}}$. The supernatants were then decanted into $50-\mathrm{mL}$ volumetric flasks and brought to $50 \mathrm{~mL}$ with deionized water. Aliquots $(2 \mathrm{~mL})$ of the extracts were stored at $-20{ }^{\circ} \mathrm{C}$ until analysis for total anthocyanin, phenolic (PHE), and tannin (TAN) concentrations.

Total ACY concentrations were spectrophotometrically determined by the $\mathrm{pH}$ differential method (Genesys 10S Vis; Thermo Fisher Scientific, Madison, WI) as described in Lee et al. (2005). Results are presented in malvidin-3-glucoside equivalents (molar extinction coefficient 28,000 $\mathrm{L} \cdot \mathrm{cm}^{-1} \cdot \mathrm{mol}^{-1}$ and molecular weight 493.3 $\left.\mathrm{g} \cdot \mathrm{mol}^{-1}\right)$. The Folin-Ciocalteu spectrophotometric assay (Waterhouse, 2002) was used to quantify PHE, was compared against gallic acid (Sigma-Aldrich, St. Louis, MO), and expressed in gallic acid equivalents. The spectrophotometric methyl cellulose precipitation assay (Sarneckis et al., 2006) was used to determine TAN, and results are reported in epicatechin equivalents using a standard curve.

Wine production. Wines were made by the collaborating commercial winery. All fruit from the field replicates of each treatment were combined, meaning that one wine lot was made per treatment in each year so that wines could undergo sensory evaluation. All wines were fermented using equal amounts of fruit to allow a uniform fermentation size across all treatments. For fermentation, fruit was destemmed, placed into 45-L plastic vessels (Main Brew, Hillsboro, OR), $50 \mathrm{mg} \cdot \mathrm{L}^{-1}$ potassium metabisulfite $\left(\mathrm{K}_{2} \mathrm{~S}_{2} \mathrm{O}_{5}\right)$ was added, and then innoculated with $\mathrm{Sac}$ charomyces cerevisiae P1Y2 (Phyterra, Napa, CA) at the manufacturer's rate. Punch downs occurred one to two times daily until yeast fermentation was complete. Wines were basket pressed once dry, settled for $24 \mathrm{~h}$, and then racked off gross lees. Thereafter, wines were inoculated for malolactic fermentation with Oenococcus oeni MT01 (Scott Laboratories, Petaluma, CA) at the manufacturer's rate. Sulfur dioxide $\left(50 \mathrm{mg} \cdot \mathrm{L}^{-1}\right)$ was added to malolactic-fermented wines using $\mathrm{K}_{2}$ $\mathrm{S}_{2} \mathrm{O}_{5}$. The wines were left to settle until they were racked off before bottling late winterearly spring into green, $750-\mathrm{mL}$ glass bottles with natural cork closures. Finished wines were stored at $13{ }^{\circ} \mathrm{C}$.

Wine sensory evaluation. After bottleaging for 2 years, wines were evaluated by consumer and commercial winemaker panels. The consumer panelists participated in two sorting tests and one overall liking test, whereas the winemaker panelists were additionally subjected to descriptive analysis. Consumer panelists had to be nonsmokers, free of oral diseases and piercings, drink red wine at least once a week, and older than 21 years of age. In 2013, 2014, and 2015, 16 (38\% male, $62 \%$ female), 18 (33\% male, $67 \%$ female), and 20 unique consumer panelists (35\% male, $65 \%$ female) participated in the analysis of 2011, 2012, and 2013 wines, respectively. Panelist ages ranged from 34 to 44 years across all years. Winemakers had to meet the aforementioned criteria and worked with commercial 'Pinot noir' production for at least 5 years. In 2013, 2014, and 2015, 16 ( $56 \%$ male, $44 \%$ female), 13 (62\% male, $38 \%$ female), and 15 professional winemakers ( $73 \%$ male, $27 \%$ female) participated in the sensory analysis of 2011, 2012, and 2013 wines, respectively.

All facilities had a mix of natural and artificial lighting, an air purifier (WAC5500; Winix, Inc., East Dundee, IL), the temperature maintained at $26{ }^{\circ} \mathrm{C}\left( \pm 3{ }^{\circ} \mathrm{C}\right)$, and portable cardboard booths (Flipside Products, Inc., Cincinnati, $\mathrm{OH})$ to separate panelists. All bottles were opened $1 \mathrm{~h}$ before tasting and $\approx 30 \mathrm{~mL}$ was poured $30 \mathrm{~min}$ before serving. Glasses were coded with random 3 -digit numbers and covered with watch glasses. Wines were presented in a random order following a balanced incomplete block design (Masuoka et al., 1995) for each test/ panelist combination. To avoid fatigue, panelists cleansed their palates with saltless saltine crackers and water after each wine and had a 5-min break between tests.

Each tasting session began with two sorting tests, one in clear glasses and one in black Institut National d'Appellation d'Origine (INAO) standard tasting glasses (ISO, 1977) presented randomly. Each sorting test was composed of a flight of six wines, one from each of the vineyard treatments. Panelists were asked to smell, taste, and then expectorate the wines. Based on their personal definition of quality, wines were sorted into three quality categories (low, medium, and high); however, there was no medium category in 2013 . There were no restrictions on the number of wines that a panelist could assign to a category. For the last test, panelists were asked to mark on a scale how much they liked each wine. In 2013 and 2014, a $100-\mathrm{mm}$ visual analog scale with word anchors "strongly dislike" and "strongly like" was used, whereas in 2015, panelists were given a scale between -5 (strongly dislike) and 5 (strongly like), with 0 representing neutral.

The professional winemaker panel session followed the same format as the consumer panel but included descriptive analysis. Panelists were given a $100-\mathrm{mm}$ visual analog scale with the word anchors "none" and "extreme" at the two ends for each aroma attribute and taste/mouthfeel characteristic listed. The aroma attributes included green, red fruit, floral, jam, spice, dark fruit, butter, and earthy, whereas the taste/mouthfeel attributes included bitter, sour, and astringency. Attributes were chosen based on previous work with 'Pinot noir' wines from Oregon's Willamette Valley.

Statistical analyses. Statistical analyses were performed on vine and berry composition data using PROC MIXED in SAS statistical software 9.3 (SAS Institute, Cary, $\mathrm{NC}$ ) for analyses of variance (ANOVA), simple linear regression, and multiple regression. Tukey's honestly significant differences (HSD) at the $\alpha=0.05$ level was used for mean separation when using ANOVAs. For relationships between crop load and berry components, linear, power, and quadratic functions were tested, and the lowest $P$ value and/or highest $R^{2}$ were used to describe the relationship. Percent ambient $P P F, Y A N$, and TAN were log-transformed as necessary to normalize residual plots and are presented as $\log$ values. The data were analyzed separately by year because of seasonal differences, with one exception described below. Using PROC GLM, ANOVA was used when considering floor management treatments as predictors, whereas simple linear or multiple regression was used when evaluating an observed characteristic or characteristics, respectively. Multiple regression analysis was performed with berry chemistry components as the dependent variable, and year, whole vine leaf area, yield, leaf blade $\mathrm{N}$, and $P P F$ as independent variables. With the exception of year, all single interactions were included. Multicollinearity was assessed through correlation plots and variance inflation factors (VIF). Using backward elimination, variables with $P$ values $>0.05$ and VIFs $>3.3$ were removed from the full model, starting with interactions. Main effects were left in the model if they were included in a significant interaction. Because these analyses were exploratory, individual variable $P$ values $\leq 0.05$ were considered significant despite multiple comparisons using the same set independent variables with potentially correlated dependent variables. Many model $P$ values were still significant using the conservative Bonferroni adjustment.

Sensory data analysis was conducted using XLStat version 2014.6.01 (Addinsoft, New York, NY), using panelists as replicates. Liking and sorting data were analyzed using ANOVA and Tukey's multiple comparison. Sorting results were analyzed by coding each grouping with 0,1 , or 2 (or only 0 and 1 for 2011 wine), with 0 being the highest quality. Panelist likeness for a wine was determined by the distance from the "highly dislike" anchor. Aroma and mouthfeel attributes were rated for intensity using the distance from the "none" anchor. Descriptive analysis data were analyzed using discriminant analysis with treatment or year as the grouping factor.

\section{Results}

Treatment effects on crop load. Floor management treatments had an inconsistent effect on LA:Y over the 3 years (Table 1). Grass had the lowest LA:Y in 2012, but there were no differences in LA:Y in other years. In all years, Y:PW was highest in Grass and lowest in Tilled. The Full Crop and Half Crop vines of all floor management treatments differed in LA:Y and $\mathrm{Y}: \mathrm{PW}-$ the direct consequence of cluster thinning. There was a significant floor management by crop level interaction in 2012 where all floor management treatments had lower Y:PW when cluster-thinned. In 2012, the largest difference in Y:PW was between Grass-Half Crop (1.9) and Grass-Full Crop (3.4). 
Treatment effects on berry composition. There were no differences in berry weight (1.1-1.3 g) among treatment combinations and years, so data are presented as concentrations in $\mathrm{mg} \cdot \mathrm{g}^{-1}$ berries (Table 2 ). The only consistent treatment effect on PHE composition in all years was $15 \%$ to $20 \%$ higher TAN concentrations in Grass than in Tilled. Grass had higher concentrations of ACY than Tilled in 2011 and higher concentrations of PHE in 2012. In 2011 and 2012, Half Crop had 12\% to $13 \%$ higher ACY than Full Crop. Conversely, Full Crop had $7 \%$ to $8 \%$ higher concentrations of TAN in 2 years (2011 and 2013).

Crop load impacts on berry composition. Because of variability by year, regressions

Table 1. Canopy and fruit ratio metrics of Oregon 'Pinot noir' vines under different vineyard floor management and crop level treatments from 2011 to 2013.

\begin{tabular}{|c|c|c|c|c|c|c|}
\hline \multirow[b]{2}{*}{ Treatments } & \multicolumn{3}{|c|}{ Leaf area:yield $\left(\mathrm{m}^{2} \cdot \mathrm{kg}^{-1}\right)^{\mathrm{z}}$} & \multicolumn{3}{|c|}{ Yield:pruning wt $\left(\mathrm{kg} \cdot \mathrm{kg}^{-1}\right)^{\mathrm{y}}$} \\
\hline & 2011 & 2012 & 2013 & 2011 & 2012 & 2013 \\
\hline \multicolumn{7}{|c|}{ Floor management $(\mathrm{F})^{\mathrm{x}}$} \\
\hline Grass & 2.1 & $1.6 \mathrm{~b}^{\mathrm{w}}$ & 2.7 & n.d. ${ }^{\mathrm{v}}$ & $2.6 \mathrm{a}$ & $2.0 \mathrm{a}$ \\
\hline Alternate & 1.7 & $2.4 \mathrm{a}$ & 3.0 & n.d. & $1.7 \mathrm{~b}$ & $1.4 \mathrm{~b}$ \\
\hline Tilled & 1.5 & $2.6 \mathrm{a}$ & 3.2 & n.d. & $1.3 \mathrm{c}$ & $1.1 \mathrm{~b}$ \\
\hline \multicolumn{7}{|c|}{ Crop level $(\mathrm{C})^{\mathrm{u}}$} \\
\hline Full Crop & $1.3 \mathrm{~b}$ & $1.7 \mathrm{~b}$ & $2.1 \mathrm{~b}$ & n.d. & $2.4 \mathrm{a}$ & $1.9 \mathrm{a}$ \\
\hline Half Crop & $2.3 \mathrm{a}$ & $2.7 \mathrm{a}$ & $3.8 \mathrm{a}$ & n.d. & $1.4 \mathrm{~b}$ & $1.1 \mathrm{~b}$ \\
\hline \multicolumn{7}{|l|}{$P$ value } \\
\hline $\mathrm{F}$ & $N S^{t}$ & $<0.001$ & NS & n.d. & $<0.001$ & $<0.001$ \\
\hline $\mathrm{C}$ & $<0.001$ & $<0.001$ & $<0.001$ & n.d. & $<0.001$ & $<0.001$ \\
\hline $\mathrm{F} \times \mathrm{C}$ & NS & NS & NS & n.d. & 0.046 & NS \\
\hline
\end{tabular}

${ }^{\mathrm{z}}$ Ratio determined from vine leaf area at véraison and yield at harvest.

${ }^{\mathrm{y}}$ Calculated using vine yield divided by vine pruning weight measured during the dormant period after harvest.

${ }^{\mathrm{x}}$ Floor management treatments include Grass - red fescue established in both alleyways flanking the vine row; Alternate - red fescue in one flanking alleyway, whereas the other was tilled; and Tilled-the two flanking alleyways were kept free of vegetation by tilling.

${ }^{\text {w} D i f f e r e n t ~ l e t t e r s ~ w i t h i n ~ c o l u m n s ~ r e p r e s e n t ~ d i f f e r e n c e s ~ b y ~ T u k e y ' s ~ h o n e s t l y ~ s i g n i f i c a n t ~ d i f f e r e n c e ~ a ~}$ $\alpha=0.05$.

${ }^{\mathrm{v}}$ n.d. $=$ not determined as pruning weight data not available

${ }^{\mathrm{u}}$ Crop level treatments included Full Crop — no clusters removed and Half Crop-fruit was thinned to one cluster per shoot $(\approx 42 \%$ clusters removed per vine)

${ }^{\mathrm{t}} \mathrm{NS}=$ not significant at $P>0.05$.

Table 2. Oregon 'Pinot noir' composition at harvest from vineyard floor management and crop level treatments 2011 to 2013 .

\begin{tabular}{|c|c|c|c|c|c|c|c|c|c|}
\hline \multirow[b]{2}{*}{ Treatments } & \multicolumn{3}{|c|}{ Anthocyanins $\left(\mathrm{mg} \cdot \mathrm{g}^{-1}\right)^{\mathrm{z}}$} & \multicolumn{3}{|c|}{ Tannins $\left(\mathrm{mg} \cdot \mathrm{g}^{-1}\right)^{\mathrm{y}}$} & \multicolumn{3}{|c|}{ Phenolics $\left(\mathrm{mg} \cdot \mathrm{g}^{-1}\right)^{\mathrm{x}}$} \\
\hline & 2011 & 2012 & 2013 & 2011 & 2012 & 2013 & 2011 & 2012 & 2013 \\
\hline \multicolumn{10}{|c|}{ Floor management $(\mathrm{F})^{\mathrm{w}}$} \\
\hline Grass & $0.47 \mathrm{a}^{\mathrm{v}}$ & 0.45 & 0.50 & $6.96 \mathrm{a}$ & $6.38 \mathrm{a}$ & $5.42 \mathrm{a}$ & 6.52 & $7.05 \mathrm{a}$ & 6.21 \\
\hline Alternate & $0.38 \mathrm{ab}$ & 0.43 & 0.45 & $6.39 \mathrm{ab}$ & $5.72 \mathrm{~b}$ & $4.82 \mathrm{ab}$ & 6.14 & $6.52 \mathrm{ab}$ & 5.86 \\
\hline Tilled & $0.35 \mathrm{~b}$ & 0.43 & 0.49 & $6.03 \mathrm{~b}$ & $5.32 \mathrm{~b}$ & $4.52 \mathrm{~b}$ & 6.06 & $6.29 \mathrm{~b}$ & 5.48 \\
\hline \multicolumn{10}{|c|}{ Crop level $(\mathrm{C})^{\mathrm{u}}$} \\
\hline Full Crop & $0.38 \mathrm{~b}$ & $0.41 \mathrm{~b}$ & 0.46 & $6.67 \mathrm{a}$ & 5.81 & $5.10 \mathrm{a}$ & 6.34 & $6.38 \mathrm{~b}$ & 5.98 \\
\hline Half Crop & $0.43 \mathrm{a}$ & $0.46 \mathrm{a}$ & 0.50 & $6.24 \mathrm{~b}$ & 5.81 & $4.74 \mathrm{~b}$ & 6.13 & $6.86 \mathrm{a}$ & 5.73 \\
\hline \multicolumn{10}{|l|}{$P$ value } \\
\hline $\mathrm{F}$ & 0.028 & $N S^{t}$ & NS & 0.023 & $<0.001$ & 0.043 & NS & 0.025 & NS \\
\hline $\mathrm{C}$ & 0.021 & 0.040 & NS & 0.003 & NS & 0.007 & NS & 0.022 & NS \\
\hline $\mathrm{F} \times \mathrm{C}$ & NS & NS & NS & NS & NS & NS & NS & NS & NS \\
\hline
\end{tabular}

${ }^{\mathrm{z}}$ Total anthocyanin concentration reported as $\mathrm{mg}$ malvidin-3-glucoside equivalents per gram of berries.

${ }^{\mathrm{y}}$ Total tannin concentration reported as mg epicatechin equivalents per gram of berries.

${ }^{\mathrm{x}}$ Total phenolic concentration reported as mg gallic acid equivalents per gram of berries.

${ }^{\mathrm{w}}$ Floor management treatments include Grass — red fescue established in both alleyways flanking the vine row; Alternate - red fescue in one flanking alleyway, whereas the other was tilled; and Tilled-the two flanking alleyways were kept free of vegetation by tilling.

'Different letters following means represent differences by Tukey's honestly significant difference at $\alpha=0.05$.

${ }^{\text {u}}$ Crop level treatments included Full Crop — no clusters removed and Half Crop-fruit was thinned to one cluster per shoot $(\approx 42 \%$ clusters removed per vine $)$.

${ }^{\mathrm{t}} \mathrm{NS}=$ not significant at $P>0.05$. to LA:Y. There was no relationship between TA and LA:Y in 2013. Yeast-assimilable N was positively correlated with LA:Y in both 2012 and $2013\left(2012: \log _{10}(y)=0.46 x+\right.$ 3.57 and 2013: $y=19.56 x+79.48)$, although the 2013 relationship was weak. There were no significant relationships between PHE and LA:Y in any year and no consistent trends between ACY and LA:Y or TAN and LA:Y.

Crop load-berry component relationships using Y:PW were best described by linear functions. In both 2012 and 2013, Y:PW was related to TA, YAN, and TAN (Table 3). TA was lower at higher Y:PW, although 2013 had a slightly lower TA (2012: $y=-0.35 x+$ 9.86 and $2013 y=-0.55 x+8.85)$. YAN was also lower at higher Y:PW in 2012 and 2013 $\left[\log _{10}(y)=-0.21 x+2.39 ; y=-62.42 x+\right.$ 229.8 , respectively]. Unlike TA and YAN, TAN was higher at higher Y:PW values in $2012\left[\log _{10}(y)=0.02 x+0.72\right]$ and $2013(y=$ $0.70 x+3.89)$. No relationships were found for $\mathrm{Y}: \mathrm{PW}$ and $\mathrm{pH}$ or $\mathrm{ACY}$.

There were few consistent relationships between yield and berry components across all years (Table 3). In 2011, yield had a relationship with all the components except TAN and PHE. However, the only two components that yield had a relationship with in more than one year were TSS and $\mathrm{pH}$. Higher yield resulted in lower TSS in 2011 and 2012 (2011: $y=-0.36 x+21.24,2012$ : $y=-0.57 x+24.64)$, but the 2012 relationship was weak. Higher yields also had lower $\mathrm{pH}$ in 2011 and $2012\left(y=3.30 x^{-0.030}\right.$ and $y=-0.046 x+3.40$, respectively). Higher yields in 2011 led to both higher TA and YAN, with only a slight upward curvature as yields increased $\left(y=7.47 x^{0.16}\right.$ and $y=74.3 x^{0.45}$, respectively). Higher yields resulted in lower ACY but had less of a decrease in ACY at yields of $\approx 3.5 \mathrm{~kg}$ per vine or higher $(y=$ $0.0051 x^{2}-0.090 x+0.72$ ).

To determine if one of the two crop load components was heavily influencing relationships between crop load and berry composition, each crop load metric (LA:Y and Y:PW) was broken down into its measured components and interactions and analyzed against each berry component through multiple regression analyses. All berry components were related to either leaf area or yield in at least 1 year (Table 4$)$. The most relationships were found between berry composition and crop load components in 2011 and very few were found in 2013. Only TSS, TA, and YAN were related to both leaf area and yield, although inconsistently so each year. The remaining berry components were related to only leaf area or yield in a given year. Tannin was the only PHE group that showed a consistent relationship with leaf area for more than 1 year. Although YAN showed a consistent relationship with leaf area, the relationship was different each year. In 2011, YAN was related to all variables and their interaction, and YAN was influenced by leaf area and yield independently in 2012 and only leaf area in 2013. Similarly, even though TSS was related to both crop load components for 
Table 3. Crop load and yield relationships to Oregon 'Pinot noir' berry components in 2011 to 2013 using floor management and cluster thinning.

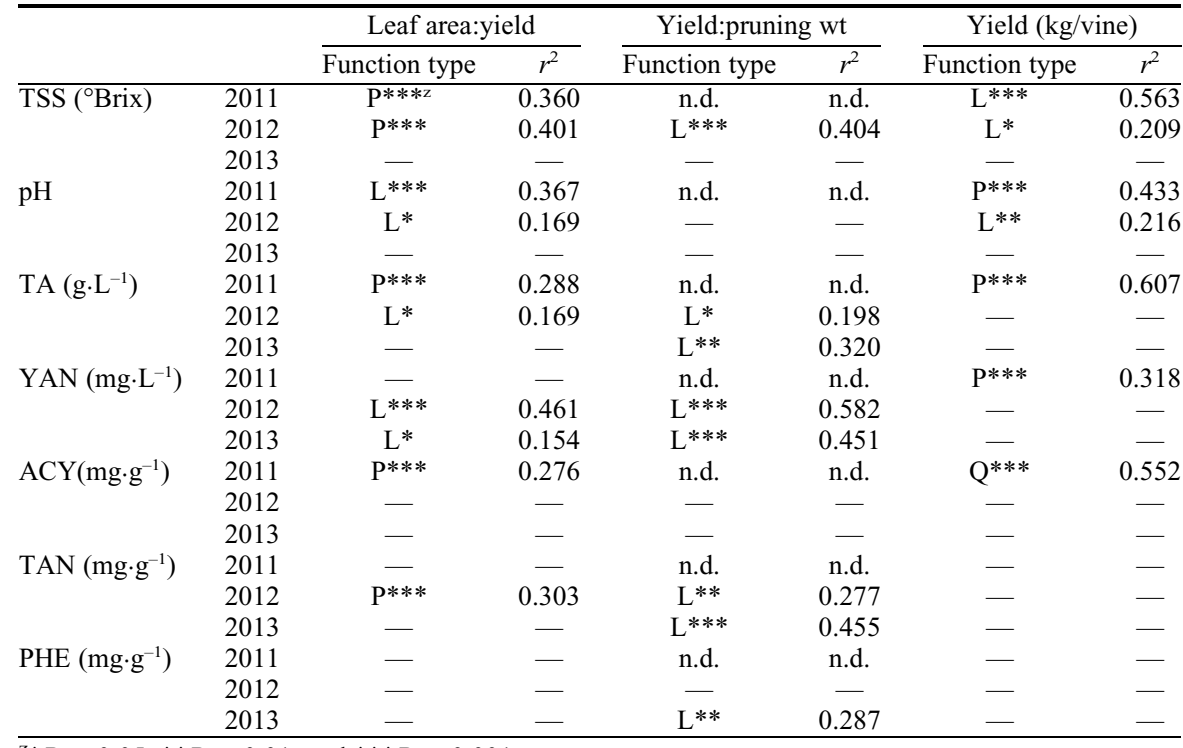

$\mathrm{z}_{*} P \leq 0.05, * * P \leq 0.01$, and $* * * P \leq 0.001$.

TSS $=$ total soluble solids; $\mathrm{L}=$ linear; $\mathrm{P}=$ power; $\mathrm{Q}=$ quadratic; n.d. $=$ not determined $;-=$ no significant relationship; TA = titratable acidity; YAN = yeast-assimilable nitrogen; the sum of primary amino acids and ammonia assays; ACY = total anthocyanin concentration reported as mg malvidin-3-glucoside equivalents per gram of berries; TAN $=$ total tannin concentration reported as $\mathrm{mg}$ epicatechin equivalents per gram of berries; $\mathrm{PHE}=$ total phenolic concentration reported as $\mathrm{mg}$ gallic acid equivalents per gram of berries.

LA:Y in 2012, TSS was related to only yield in 2011 and only leaf area in 2013.

There were no interactive effects between pruning weight and yield on berry composition (Table 5). Only TSS and TAN were related to both pruning weight and yield in 1 year. YAN was consistently influenced by only pruning weight as higher pruning weights were related to higher YAN. In both years, there was a weak association between PHE and pruning weight. Tannin concentration was related to pruning weight in both years but was also related to yield in 2013. Pruning weight and yield were not related to $\mathrm{pH}, \mathrm{TA}$, or ACY (Table 5).

Leaf blade $N$ impacts on berry composition. Because vineyard floor management influenced vine growth and tissue $\mathrm{N}$ status, it was expected that $\mathrm{N}$ effects on the canopy (pruning weight and leaf area) would influence berry $\mathrm{N}$ composition. Total soluble solids and YAN had relationships with leaf blade $\mathrm{N}$ each year (data not shown). There was a negative linear relationship with leaf blade $\mathrm{N}$ and TSS in $2011\left(P=0.031, r^{2}=\right.$ $0.16)$, whereas TSS was greater at higher leaf blade $\mathrm{N}$ in 2012 and $2013(P=0.049$ and 0.001 , and $r^{2}=0.13$ and 0.31 , respectively). However, the 2011 and 2012 relationships were weak. With increasing leaf blade N, TA was higher in 2011 and 2012 but lower in $2013\left(P<0.001, r^{2}=0.49 ; P=0.002, r^{2}=\right.$ 0.29 ; and $P=0.011, r^{2}=0.21$, respectively). As expected, the strongest relationships were between YAN and leaf blade N, with higher YAN associated with higher leaf blade $\mathrm{N}(P<$ 0.001 all years; $r^{2}=0.69, r^{2}=0.44$, and $r^{2}=$ 0.66 in 2011, 2012, and 2013, respectively). Generally, TAN and PHE were lower with higher leaf blade $\mathrm{N}$, except there was no relationship with PHE in 2012.

Light environment effects. The relationships between berry composition and vegetative measures may be related to $\mathrm{N}$ effects on canopy growth and microclimate, particularly light infiltration through the fruit zone. Vegetative measures and leaf blade $\mathrm{N}$ influenced $P P F$ as higher pruning weight, leaf area, and leaf blade $\mathrm{N}$ resulted in lower $P P F$ (Fig. 2). There were no consistent relationships between berry components and $P P F$ in the morning or at solar noon in any year (data not shown), and afternoon measurements were only taken in 2012 and 2013. There were no relationships between ACY and $P P F$ during any phenological time point measured (data not shown). However, PHE and TAN were higher with higher $P P F$ at véraison in 2012 and 2013 (Fig. 3). In addition, TA was lower at higher $P P F$ at the veraison and ripening time points in both years $(P \leq 0.042)$.

Because leaf area, yield, leaf blade $\mathrm{N}$, and $P P F$ are physiologically linked, multiple regressions with these measures and their interactions were assessed against each berry component controlling for the effect of year. All berry components, except ACY, were influenced by year, and no significant interactions were found (Table 6). With the exception of ACY, whenever yield was related to a berry component, year was also a factor, which was anticipated, given the high yields in 2011 compared with the other 2 years. With the exception of PHE, whenever leaf blade $\mathrm{N}$ was significant, leaf area or $P P F$ were also significant, although no interactions were found for any berry components.
Total soluble solids were related to yield and leaf area but were affected by year as well. This supports our previous findings where TSS was related to leaf area in some years, whereas it was related to yield or both leaf area and yield in other years. TA was related to all factors analyzed except leaf area. Although it was expected that YAN would be influenced by leaf blade N, YAN was also related to year and leaf area. Only TAN and TA were influenced by $P P F$.

Wine sensory analysis. Wines produced from 2011 and 2012 did not differ by descriptive analyses, sorting, or liking by either consumer or winemaker panels, although both panels found differences among 2013 wines. Wines from the 2013 vintage were differentiated through descriptive analysis by winemakers with Grass-Half Crop statistically separated from all other treatments (Fig. 4). Grass-Half Crop wine was described as having more intense floral and jam aromas and sour taste. There was some statistical separation between other wines, but overall, they were described as more green, earthy, buttery, and had an astringent mouthfeel.

Quality differences were found by both consumer and winemaker panels when sorting 2013 wines into high-, medium-, and low-quality categories. Consumers, when presented wines in clear glasses, considered Alternate-Full Crop and Grass-Half Crop to be the highest quality and Tilled-Half Crop to be the lowest quality $(P=0.021)$. However, when the wines were presented in black glasses, consumers did not find differences in quality among the wines $(P=0.754)$. Conversely, winemakers were not able to separate 2013 wines into different quality categories when presented in clear glasses $(P=0.655)$, but they could discern differences when wines were served in black glasses $(P=0.004)$. Like consumers, winemakers thought Alternate-Full Crop was one of the highest quality, but unlike consumers, they thought Alternate-Half Crop was also of high quality and Tilled-Full Crop to be of low quality. Despite the ability to sort wines into different quality groups, the winemaker and consumer panels did not have a preference for any wine based on liking scores $(P=$ 0.802 and 0.120 , respectively).

\section{Discussion}

Treatment effects on crop load. Both crop load metrics, Y:PW and LA:Y, were strongly affected by crop level treatments. However, the effects of floor management treatments were less clear, as differences among floor management treatments were generally found for Y:PW but not LA:Y. Unlike studies that involve the deliberate removal of leaf area or fruit to alter crop load, the floor management treatments in this study affected both yield and canopy size naturally in a field setting. As previously reported for this study (Reeve et al., 2016), there were clear differences in canopy size among floor management treatments, with mean véraison leaf area of $4.6 \mathrm{~m}^{2}$ per vine for Grass vines and 

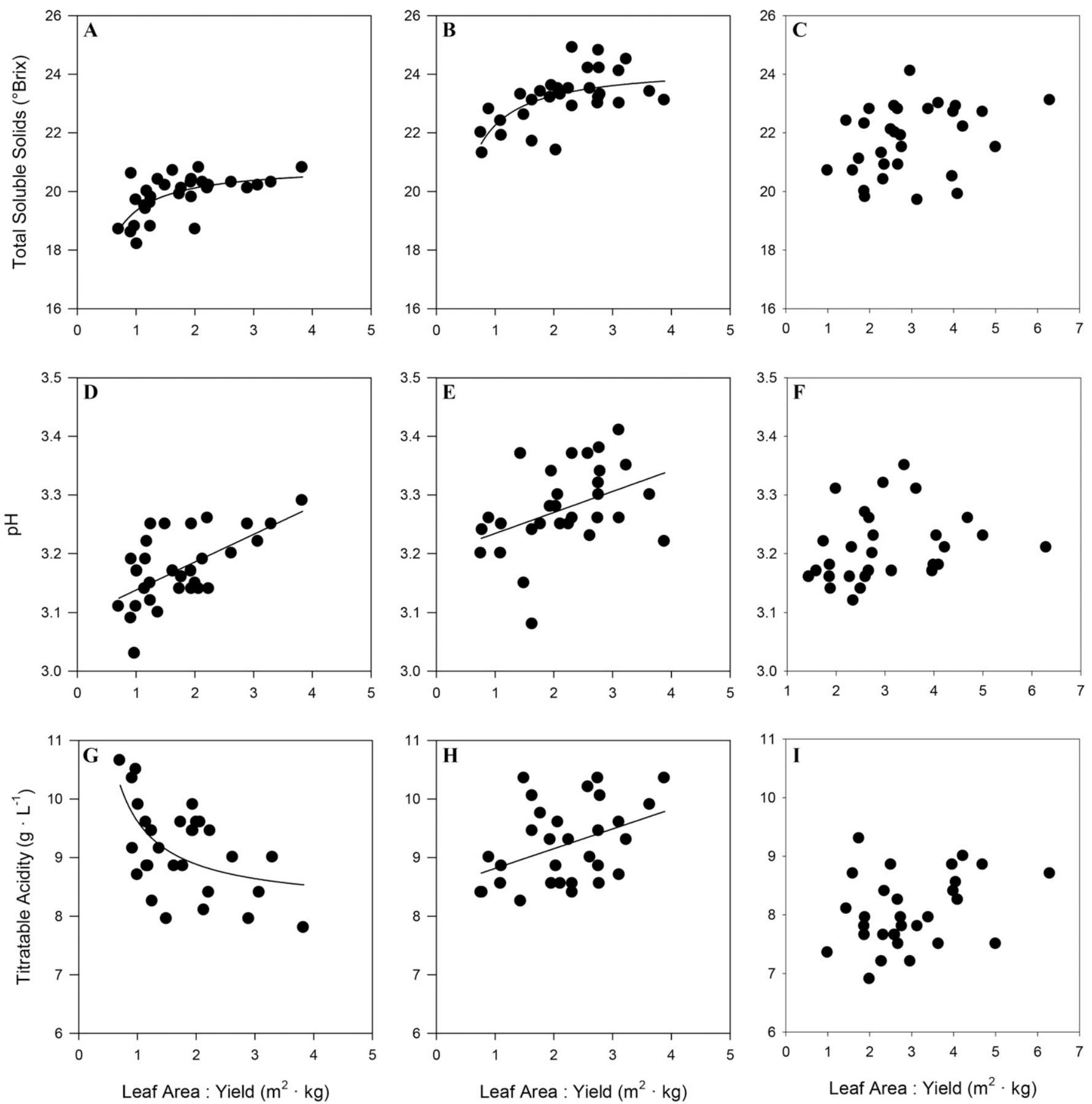

Fig. 1. Influence of the leaf area to yield ratio of Oregon 'Pinot noir' on total soluble solids (A-C), pH (D-F), and titratable acidity (G-I) in 2011 (A, D, and G), 2012 (B, E, and H), and 2013 (C, F, and I). (A) $y=19.37 x^{0.050}, P<0.001 ;(\mathbf{B}) y=22.26 x^{0.057}, P<0.001 ;$ (D) $y=0.047 x+3.09, P<0.001 ;$ (E) $y=0.036 x+3.20$, $P=0.024 ;(\mathbf{G}) y=9.60 x^{-0.10}, P<0.001 ;(\mathbf{H}) y=0.34 x+8.48, P=0.024$.

$6.8 \mathrm{~m}^{2}$ per vine for Alternate and Tilled vines over all years. Similarly, the 2-year mean pruning weights were $0.9,1.6$, and $1.9 \mathrm{~kg}$ per vine for Grass, Alternate, and Tilled vines, respectively. Yields were also affected by floor management treatments as Grass, Alternate, and Tilled vines averaged 2.3, 3.0, and $3.1 \mathrm{~kg}$ per vine, respectively, over all years. The reduced canopy size and yields of Grass vines were attributed to lower vine N. Similarly, others have noted physiological reduction in yield and leaf area in response to lower vine N status (Christensen et al., 1994;
Schreiner and Scagel, 2017; Schreiner et al., 2013).

Because of the concurrent reductions in yield and leaf area in Grass vines, the effect of floor management treatments on crop load depended on which crop load metric was used. Grass vines had less source (canopy size) and thus were considered to have a greater sink demand when estimating crop load by Y:PW. Despite clearly different canopy sizes and yield in Grass and Tilled vines, both had similar LA:Y in 2 of the 3 years. In 2012, yields were similar across treatments, but LA:Y differed by floor management treatment. Interestingly, this was also the only year that TSS differed by floor management treatments as Grass vines had the lowest TSS and Tilled vines had the highest TSS (Reeve et al., 2016). This suggests that Tilled vines had a larger source to sink ratio compared with Grass vines. The lack of differences in TSS among floor management treatments in the other 2 years suggests that Grass and Tilled vines had comparable source to sink ratios, as shown by similar LA:Y values, despite contrasting 
Table 4. Effects of véraison leaf area and yield on Oregon 'Pinot noir' berry composition under different floor management and crop levels in 2011 to 2013.

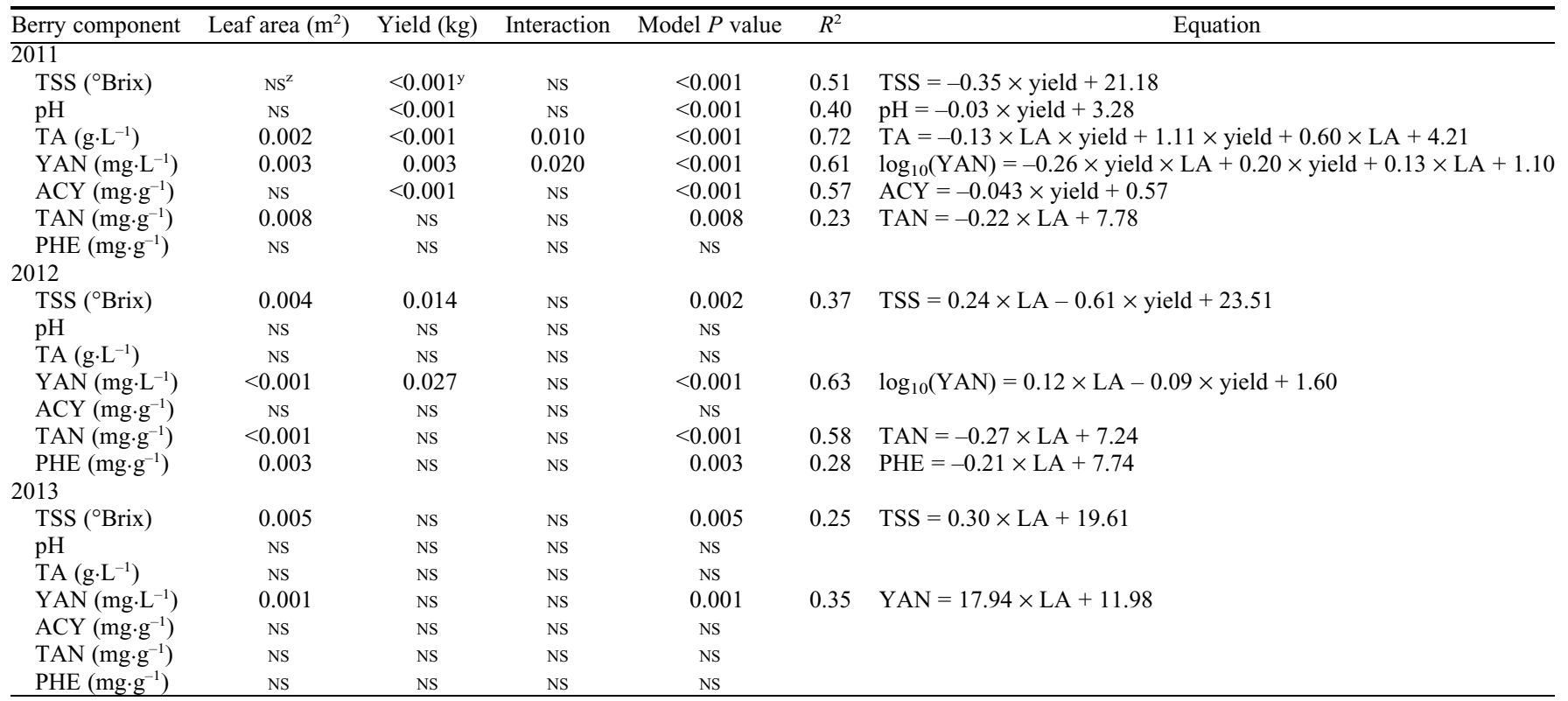

$\mathrm{z}_{\mathrm{NS}}=$ not significant at $P>0.05$, so variable removed from model.

${ }^{\mathrm{y}} P$ value for predictor variable in model.

TSS = total soluble solids; TA = titratable acidity; YAN = yeast-assimilable nitrogen; the sum of primary amino acids and ammonia assays and was logtransformed in 2011 and 2012; ACY = total anthocyanin concentration reported as mg malvidin-3-glucoside equivalents per gram of berries; TAN = total tannin concentration reported as $\mathrm{mg}$ epicatechin equivalents per gram of berries; PHE = total phenolic concentration reported as mg gallic acid equivalents per gram of berries.

Table 5. Multiple regression analyses of dormant vine pruning weight and yield with Oregon 'Pinot noir' berry composition under varying floor management and crop levels in 2012 and 2013.

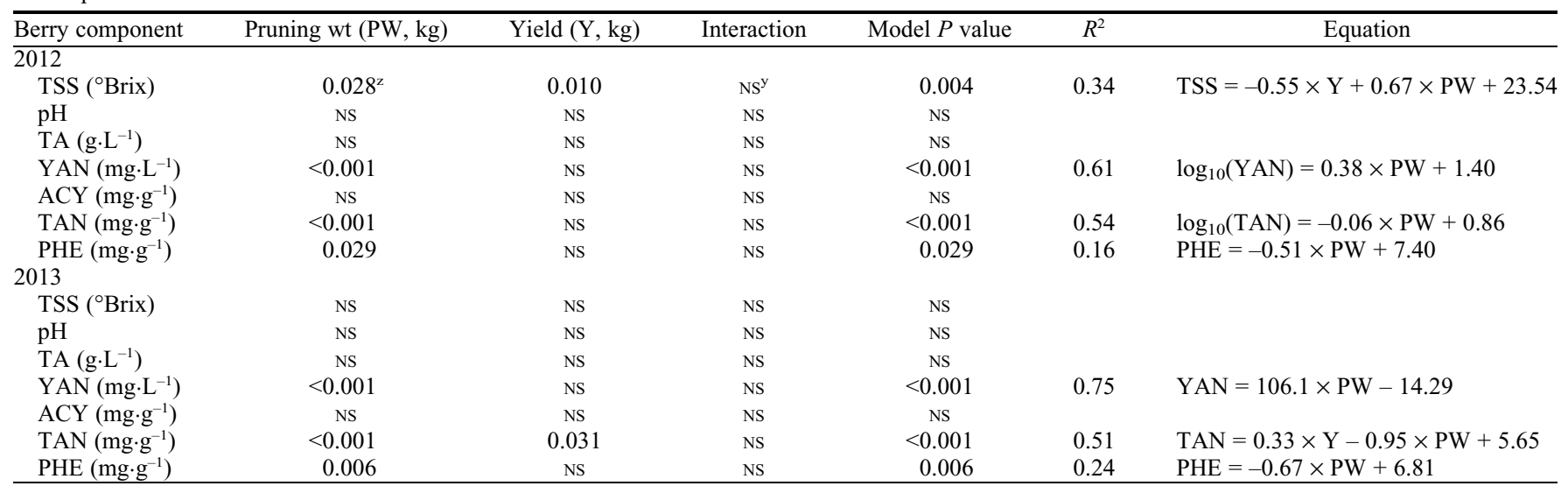

${ }^{\mathrm{z} P}$ value for predictor variable in model.

$\mathrm{y}_{\mathrm{NS}}=$ not significant at $P>0.05$, so variable removed from model.

TSS = total soluble solids; TA = titratable acidity; YAN = yeast-assimilable nitrogen; the sum of primary amino acids and ammonia assays and was logtransformed in 2012; ACY = total anthocyanin concentration reported as mg malvidin-3-glucoside equivalents per gram of berries; TAN = total tannin concentration reported as mg epicatechin equivalents per gram of berries; PHE $=$ total phenolic concentration reported as mg gallic acid equivalents per gram of berries.

canopy sizes and fruit yields. These results exemplify the concept of vine capacity under different conditions as both treatments were able to physiologically adjust yields and canopy size without the use of manual canopy or crop management (Keller et al., 2005; Koblet et al., 1994).

It is likely that the lack of consistency between crop load metrics in this study was influenced by commercial canopy management practices. The single-curtain VSP system was hedged mechanically with multiple passes to avoid overgrowth and shading beyond the confines of the trellis system. Leaf area measurements were conducted based on phenology each year to estimate vine size differences between treatments, and similar amounts of leaf area were measured between Alternate and Tilled vines in all years. This suggests that the amount of leaf area measured at véraison was the amount that filled the volume created by the hedger and was the maximum leaf area attainable in this study (Reeve et al., 2016). However, differences in pruning weight were found between Alternate and Tilled vines (Reeve et al., 2016), indicating differences in vine size, namely, cane girth, which was not captured by leaf area assessments.
Leaf area to yield. There have been many reports of relationships between LA:Y and TSS cited in the literature, although limited studies have examined the relationship between LA:Y and other berry components (Kliewer and Dokoozlian, 2005; Kliewer and Weaver, 1971; Naor et al., 2002; Reynolds et al., 1994). In this study, LA:Y ranged from 0.7 to $6.3 \mathrm{~m}^{2} \cdot \mathrm{kg}^{-1}$ with an average of $2.3 \mathrm{~m}^{2} \cdot \mathrm{kg}^{-1}$ over all years. The relationships between TSS and LA:Y in 2011 and 2012 were curvilinear, similar to many other studies (Kaps and Cahoon, 1992; Kliewer, 1970; Kliewer and Antcliff, 1970; May et al., 1969; Naor et al., 

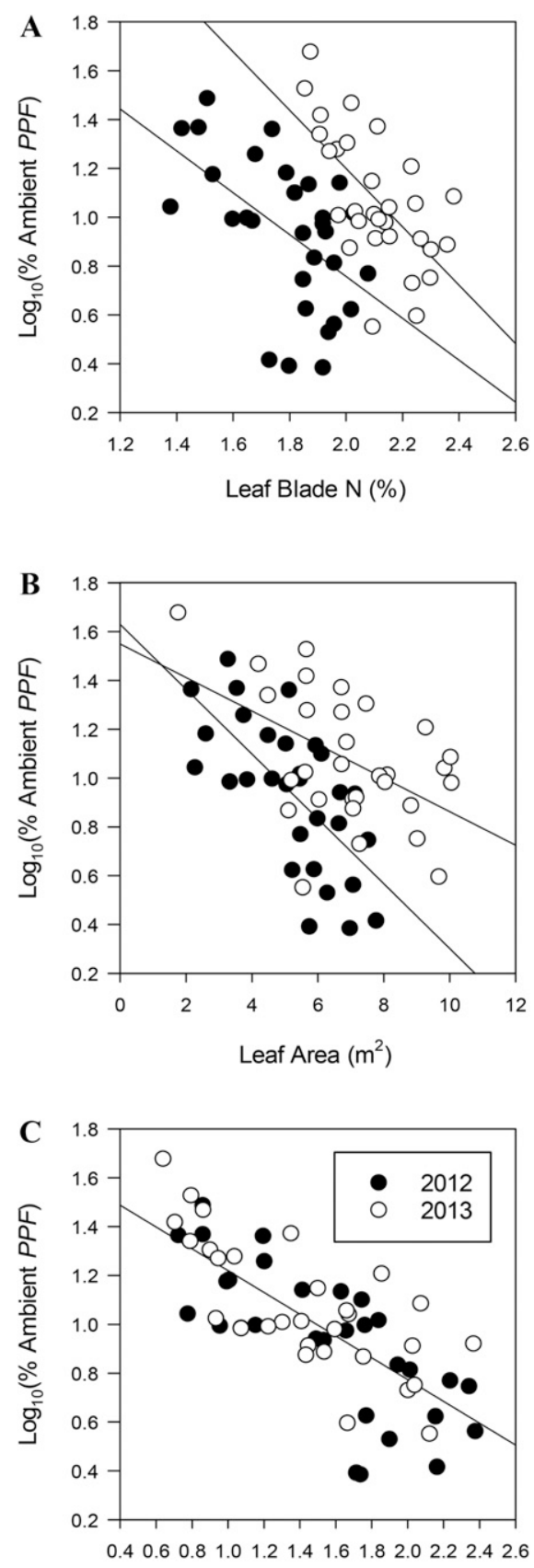

Pruning Weight (kg)

Fig. 2. Influence of leaf blade N (A), leaf area (B), and pruning weight $(\mathbf{C})$ on the percent of ambient photosynthetic photon flux $(P P F)$ infiltrated through the fruit zone of Oregon 'Pinot noir' during an afternoon at véraison. Leaf blade and leaf area data were collected at véraison, whereas pruning weight data were collected the winter after the growing season. (A) Leaf blade N $P<0.001$, year $P<0.001$, model $P<0.001, R^{2}=0.37(2012: y=-0.98 x+$ 2.70, 2013: $y=-0.98 x+3.14)$. (B) Leaf area $P<$ 0.001 , year $P<0.001$, model $P<0.001, R^{2}=$ 0.37 (2012: $y=-0.09 x+1.46,2013: y=-0.09 x+$ 1.73). (C) Pruning weight $P<0.001$, year and interaction not significant, $R^{2}=0.56$ $(y=-0.45 x+1.67)$.

2002), although not all (Keller et al., 2005). The LA:Y range where TSS plateaued was similar in 2 of 3 years, at $\approx 1.25-1.75 \mathrm{~m}^{2} \cdot \mathrm{kg}^{-1}$, and represents the crop load at which further increases in leaf area or decreases in yield had little influence on TSS. This is higher than the $0.8-1.2 \mathrm{~m}^{2} \cdot \mathrm{kg}^{-1}$ suggested by Kliewer and Dokoozlian (2005); however, those guidelines were for single-canopy wine grapes in a warm region. Although the crop load plateau was similar in 2 years of our study, it cannot be interpreted as the amount of leaf area needed to ripen 'Pinot noir' under the cool climate of western Oregon. Climatic conditions varied significantly between 2011 (cool year) and 2012 (warm year), thereby resulting in 2011 having much lower TSS than 2012 at all LA:Y values achieved (Reeve et al., 2016). The crop level treatments in this study decreased the yield by $\approx 40 \%$; however, further decreases in yield (and thus increases in LA:Y) would have little effect as LA:Y greater than $1.5 \mathrm{~m}^{2} \cdot \mathrm{kg}^{-1}$ were not able to reach commercially accepted maturity in 2011. These results suggest that climate and variable seasonal weather serve as greater limitations to consistently ripening fruit, and that crop load adjustments can only affect TSS to a certain extent and may not be able to compensate for seasonal or climatic limitations of a given region (Frioni et al., 2017). For example, similar LA:Y values were achieved in 2013 compared with the prior 2 years, yet there was no relationship between LA:Y and TSS. The 2013 season had intermediate heat units from budbreak to harvest and lower yields, and this suggests that the climatic conditions did not limit TSS accumulation, given the yields observed in that year (Reeve et al., 2016). Likewise, utilization of crop-load metrics may be better suited for regions and climates where canopies are under less manipulation and where a given cultivar can ripen consistently.

Similar to the findings for TSS, LA:Y was also related to $\mathrm{pH}$ and TA in 2011 and 2012. Crop load (LA:Y) influenced $\mathrm{pH}$ in 2011 and 2012, but the yield explained this relationship in 2011 because it was the highest yielding and coolest year. Unlike $\mathrm{pH}$, both leaf area and yield likely influenced TA, but this relationship was only apparent in 2011. In 2012 and 2013, LA:Y was also related to YAN.

Yield to pruning weight. Grass vines had a higher Y:PW ratio than Tilled vines because of a greater reduction in pruning weight ( $50 \%$ to $54 \%$ ) than yield ( $0 \%$ to $19 \%$ ) (Reeve et al., 2016). The Y:PW in this study ranged from $0.5-3.7$, which is considerably lower than the suggested 3-6 for Oregon 'Pinot noir' (Kliewer and Casteel, 2003) or the more commonly used metric of 5-10 suggested by Kliewer and Dokoozlian (2005). 'Pinot noir' in British Columbia had 4-year averages ranging from 8 to 13 without reported detrimental effects on TSS, TA, $\mathrm{pH}$, and color (Reynolds et al., 1994). However, their greater crop loads were achieved using a divided canopy training system, allowing for better canopy light attenuation and greater yields. In addition, the yields in that study were reported to be higher than a study concurrently conducted in the Willamette Valley (Reynolds et al., 1996). In our study, a higher Y:PW
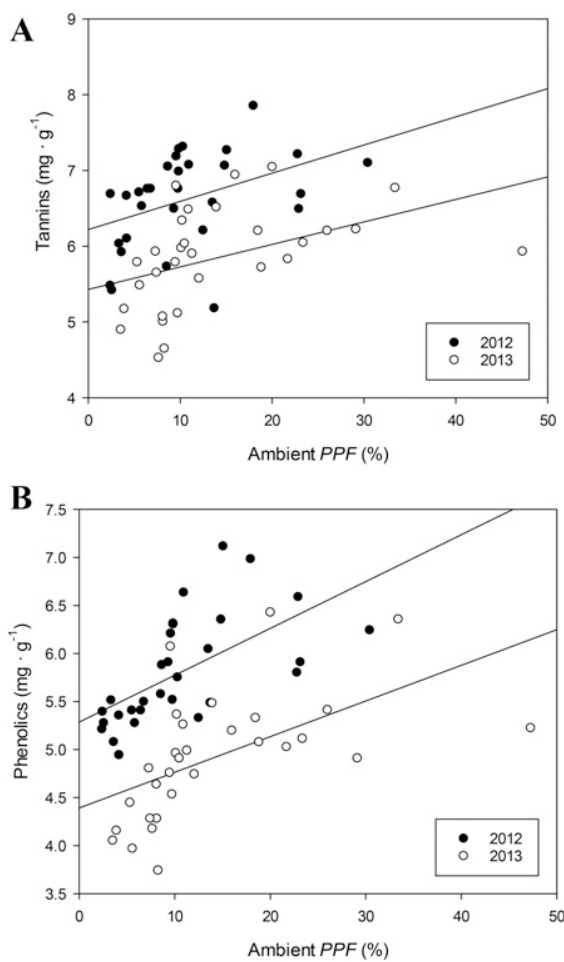

Fig. 3. Effect of fruit zone light infiltration [percent ambient photosynthetic photon flux $(P P F)]$ of Oregon 'Pinot noir' in the afternoon during véraison on (A) total tannin and (B) total phenolic concentration of 'Pinot noir' berries. Tannins: year $P<0.001$, ambient $P P F P<$ 0.001 , interaction not significant, model $P<$ $0.001, r^{2}=0.57(2012: y=0.041 x+5.37,2013:$ $y=0.041 x+4.34)$. Phenolics: year $P \leq 0.001$, ambient $P P F P<0.001$, interaction not significant, model $P<0.001, r^{2}=0.40$ (2012: $y=$ $0.032 x+6.27,2013: y=0.032 x+5.39)$.

range was observed in 2011 because of the high yields that year, but unfortunately pruning weight data were not available to make these comparisons.

The Y:PW ratio was shown to be an important indicator of berry composition as more relationships were found than with LA: $\mathrm{Y}$ in 2012 and 2013. Given this research was conducted in the field, low $r^{2}$ values were expected, especially because of the low yields exhibited in these years with 'Pinot noir', resulting in a narrow range of $\mathrm{Y}: \mathrm{PW}$ and LA:Y. Similar to LA:Y, TSS was influenced by $\mathrm{Y}: \mathrm{PW}$ in 2012, with both yield and pruning weight contributing to this relationship. Despite TA, YAN, and TAN also having relationships with $\mathrm{Y}: \mathrm{PW}$, none of them were related to both yield and pruning weight, suggesting that these components are also influenced by factors other than carbohydrate partitioning.

Yield. Cluster thinning is a common practice used by 'Pinot noir' producers in Oregon's Willamette Valley because it is believed to maintain a premium standard and promote ripening. However, most of those producers target a specific yield (4.5$6.2 \mathrm{t} \cdot \mathrm{ha}^{-1}$ ) across diverse vineyards rather than using canopy to yield metrics to ensure 
Table 6. Multiple regression analyses of viticulture measures for Oregon 'Pinot noir' berry components under different floor management and crop levels for 3 years.

\begin{tabular}{|c|c|c|c|c|c|c|c|c|c|}
\hline Berry component & $\operatorname{Yr}(\mathrm{R})$ & Yield $(\mathrm{Y})^{\mathrm{z}}$ & $\begin{array}{c}\text { Leaf } \\
\text { area }(\mathrm{LA})^{\mathrm{y}}\end{array}$ & $\begin{array}{l}\text { Leaf Blade } \\
\text { Nitrogen }(N)^{x}\end{array}$ & $P P F(\mathrm{P})^{\mathrm{w}}$ & Model & $R^{2}$ & $\mathrm{cv}$ & Equation \\
\hline $\mathrm{pH}$ & $<0.001$ & $<0.001$ & NS & NS & NS & $<0.001$ & 0.46 & 1.8 & $\begin{array}{l}\mathrm{pH}=3.35-0.06 \times(\mathrm{R}=2011)-0.09 \times(\mathrm{R}=2013) \\
\quad-0.03 \times \mathrm{Y}\end{array}$ \\
\hline $\mathrm{TA}\left(\mathrm{g} \cdot \mathrm{L}^{-1}\right)$ & $<0.001$ & 0.009 & NS & 0.001 & 0.001 & $<0.001$ & 0.68 & 5.7 & $\begin{array}{l}\mathrm{TA}=6.91-0.39 \times(\mathrm{R}=2011)-1.42 \times(\mathrm{R}=2013) \\
\quad+0.15 \times \mathrm{Y}-0.08 \times \mathrm{P}+1.21 \times \mathrm{N}\end{array}$ \\
\hline YAN $\left(\mathrm{mg} \cdot \mathrm{L}^{-1}\right)$ & $<0.001$ & NS & 0.002 & $<0.001$ & NS & $<0.001$ & 0.59 & 29.0 & $\begin{array}{l}\mathrm{YAN}=-250.53-63.38 \times(\mathrm{R}=2011)-45.45 \\
\quad \times(\mathrm{R}=2013)+175.50 \times \mathrm{N}+9.13 \times \mathrm{LA}\end{array}$ \\
\hline TAN (mg.g $\left.\mathrm{g}^{-1}\right)$ & $<0.001$ & NS & NS & $<0.001$ & 0.004 & $<0.001$ & 0.70 & 8.7 & $\begin{array}{l}\text { TAN }=7.93+0.86 \times(\mathrm{R}=2011)-0.51 \times(\mathrm{R}=2013) \\
\quad+0.07 \times \mathrm{P}-1.31 \times \mathrm{N}\end{array}$ \\
\hline PHE (mg. $\left.\mathrm{g}^{-1}\right)$ & $<0.001$ & NS & NS & $<0.001$ & NS & $<0.001$ & 0.33 & 8.8 & $\begin{array}{l}\mathrm{PHE}=8.71+0.15 \times(\mathrm{R}=2011)-0.40 \times(\mathrm{R}=2013) \\
\quad-1.17 \times \mathrm{N}\end{array}$ \\
\hline
\end{tabular}

${ }^{\mathrm{z}}$ Vine yield measured at harvest $(\mathrm{kg})$.

${ }^{\mathrm{y}}$ Vine leaf area measured at véraison $\left(\mathrm{m}^{2}\right)$.

${ }^{\mathrm{x}}$ Nitrogen concentration in leaf blades at véraison (\%).

${ }^{\mathrm{w}} P P F$ (photosynthetic photon flux) infiltration through the fruit zone at solar noon during $1 \mathrm{~d}$ during véraison.

$\mathrm{v}_{\mathrm{NS}}=$ not significant at $P>0.05$.

TSS = total soluble solids; TA = titratable acidity YAN = yeast-assimilable nitrogen; the sum of primary amino acids and ammonia assays; $\mathrm{ACY}=$ total anthocyanin concentration reported as $\mathrm{mg}$ malvidin-3-glucoside equivalents per gram of berries; TAN = total tannin concentration reported as $\mathrm{mg}$ epicatechin equivalents per gram of berries; $\mathrm{PHE}=$ total phenolic concentration reported as mg gallic acid equivalents per gram of berries.

quality (Uzes and Skinkis, 2016). Yield was generally not a better predictor of berry composition than crop load metrics, and Y: PW related to berry composition more often than yield alone. Relationships between yield and berry composition were primarily limited to 2011, the highest yielding and coolest season where delayed ripening led to more differences at harvest than is typical for the region or the 3 -year period of this study. However, yield was the main factor determining $\mathrm{pH}$ in this study, but this was best observed when yield was high. For example, LA:Y influenced $\mathrm{pH}$ in 2011 and 2012, but yield could explain this relationship in 2011. This was supported through multiple regression with all factors, as only yield and year were contributors. This suggests that the relationship between $\mathrm{pH}$ and yield may only be evident in higher yielding years.

Although increases in 'Pinot noir' ACY have been associated with light exposure in several studies (Feng et al., 2015; Lee and Skinkis, 2013), there was no relationship between ACY and PPF in this study despite differences in canopy size. Yield was the factor that influenced ACY most across the 3-year study with lower yields leading to higher ACY, with the strongest relationship in the highest yielding year (2011). However, higher yield with more clusters in the fruit zone would have reduced light infiltration due to cluster occlusion in 2011. Studies have shown increased ACY with decreasing yield in 'Nebbiolo' (Guidoni et al., 2002) and 'Pinot noir' (Reynolds et al., 1994, 1996; Vance, 2012), but these studies do not address the potential light effects. Interestingly, Kliewer and Weaver (1971) found a curvilinear relationship between LA:Y and coloration of fruit, with coloration of 'Tokay' grapes reaching a plateau at higher LA:Y.

Light environment and leaf blade $N$. Although vine $\mathrm{N}$ status and $P P F$ are often related because of the canopy growth effects of high or low $\mathrm{N}$ status, they cannot be separated within the bounds of this study.

Nitrogen had few relationships with berry components that were not also explained by canopy size, $P P F$, or yield. This was not surprising because $\mathrm{N}$ is one of the most important mineral nutrients for grapevine growth. It can have a strong effect on yield, leaf area, and pruning weight in 'Pinot noir' (Schreiner and Scagel, 2017).

However, there were instances where $\mathrm{N}$ alone may have influenced berry components, most notably YAN, or in association with PPF, TAN, and PHE. Both TAN and PHE were linearly related to leaf blade $\mathrm{N}$ and $P P F$, although no relationship existed between PHE and leaf blade $\mathrm{N}$ in 2012. However, when both $P P F$ and leaf blade $\mathrm{N}$ were considered together, PHE was not related to $P P F$. There have been mixed results between $\mathrm{N}$ and PHE from other studies. Lower PHE have been found with high $\mathrm{N}$ vines for 'Tempranillo' (Delgado et al., 2004) and 'Pinot noir' (Schreiner et al., 2014), which was independent of $P P F$ in the latter study. Keller and Hrazdina (1998) also found higher total PHE concentrations in 'Cabernet sauvignon' berry skins of lower $\mathrm{N}$ vines under the same $P P F$ at some points during ripening but not at harvest. However, there were higher concentrations of PHE found in more-exposed fruit in several other studies (Dokoozlian and Kliewer, 1996; Morrison and Noble, 1990; Price et al., 1995; Spayd et al., 2002).

In this study, both $\mathrm{N}$ and $P P F$ can be related to TAN independently of each other. In a number of cultivars, Ough et al. (1968) did not find differences in TAN concentrations in juice between $\mathrm{N}$-fertilized and unfertilized vines. Delgado et al. (2004) found lower total TAN in berry skins from $\mathrm{N}$-fertilized vines at véraison but not at harvest. Downey et al. (2004) did not find a relationship between cluster shading and concentrations of TAN in 'Shiraz' skins or seeds. However, Price et al. (1995) found that wine from more-exposed 'Pinot noir' clusters had higher berry quercetin glycosides but lower catechin and epicatechin concentrations.

In our study, there was no consistent factor that influenced TA. Yield, leaf blade $\mathrm{N}$, and $P P F$ were related to TA based on multiple regression analyses, but yield was only related to TA in the highest yielding year (higher yields and higher TA). Furthermore, TA had inconsistent relationships with leaf blade $\mathrm{N}$ each year, similar to other research with 'Pinot noir' (Schreiner et al., 2013). However, higher $P P F$ in our study was associated with lower TA. The relationship between leaf blade $\mathrm{N}$ and yield may be indirect and possibly the consequence of the more direct effects that $\mathrm{N}$ has on vine growth and intercepted $P P F$. In addition, yield may affect light infiltration of the fruit zone, particularly in high-yielding years when clusters overlap or when cluster thinning removes light-occluding clusters. Lower TA has been associated with higher temperature and cluster exposure (Reynolds et al., 1986; Spayd et al., 2002). However, only light was measured in this study; temperature may have been a confounding effect.

There was a positive linear relationship between leaf blade $\mathrm{N}$ at véraison and YAN. Many studies have shown positive relationships between tissue $\mathrm{N}$ and nitrogenous compounds in the juice of 'Riesling' (Spayd et al., 1994), 'Merlot' (Hannam et al., 2013; Neilsen et al., 2010), and 'Pinot noir' (Lee and Schreiner, 2010; Reeve et al., 2016; Schreiner and Scagel, 2017; Schreiner et al., 2013). Ough et al. (1968) also found that juice $\mathrm{N}$ increased linearly with $\mathrm{Y}: \mathrm{PW}$ when tested across five white and five red cultivars. We found a similar linear relationship with higher YAN associated with larger canopy size relative to yield. However, these relationships were only found in the lowest yielding years. Further statistical analyses indicated that pruning weight had greater 

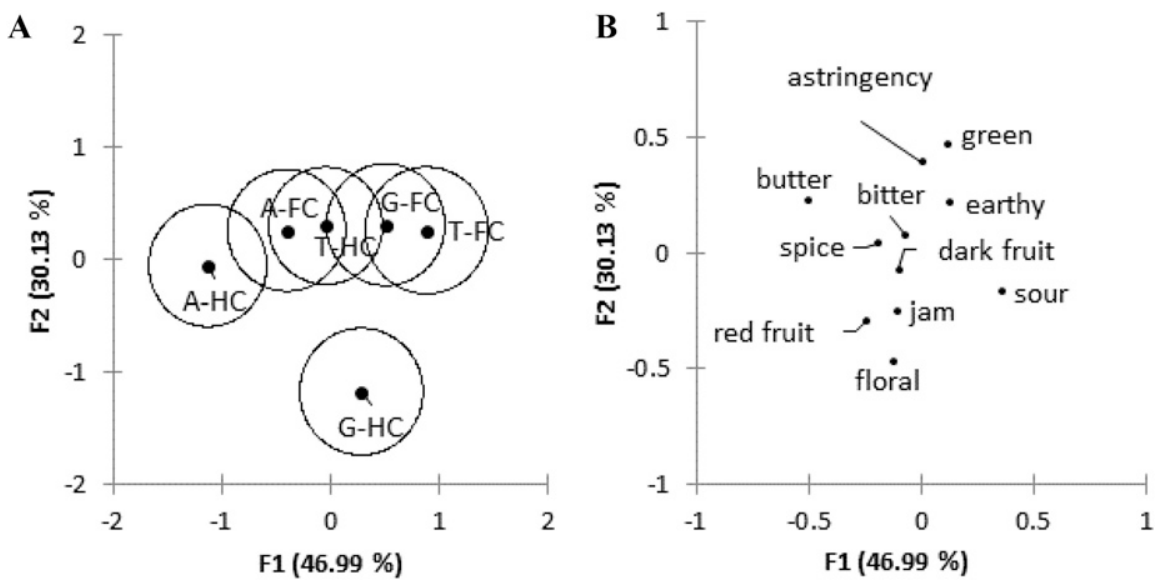

Fig. 4. Separation of the 2013 'Pinot noir' wines based on canonical variate analysis by treatment scores (A) and sensory loadings (B) obtained from a winemaker sensory panel. Treatments are positioned using centroids with circles representing 95\% confidence intervals surrounding the treatment means $\mathrm{G}=$ Grass; $\mathrm{A}=$ Alternate; $\mathrm{T}=$ Tilled $\mathrm{HC}=$ Half Crop; $\mathrm{FC}=$ Full Crop.

impact and was influenced by leaf blade $\mathrm{N}$, suggesting that the relationships found in other studies (Kliewer and Weaver, 1971; Ough et al., 1968) may have been due to vine $\mathrm{N}$ status rather than crop load.

Wine sensory evaluation. Only the 2013 wines differed between treatments, and differences were apparent to both consumers and winemakers. However, relating wine quality rankings to measures of crop load proved challenging. Wines that were considered of higher quality had LA:Y ratios between 3.2 and $5.1 \mathrm{~m}^{2} \cdot \mathrm{kg}^{-1}$, whereas the wines from the lower quality group had LA:Y ratios that encompassed that range (2.7 and $\left.6.1 \mathrm{~m}^{2} \cdot \mathrm{kg}^{-1}\right)$. Similar results were found when using Y:PW as the crop load metric, as one of the treatments (Tilled-Full Crop, 1.5 Y:PW) considered to be of low quality had a Y:PW between two treatments (Alternate-Half Crop, 1.0 and Alternate-Full Crop, 1.7) that were considered to be of high quality. In addition, both the highest and lowest yielding treatments were grouped in the high quality category (Alternate-Full Crop and Grass-Half Crop, respectively). Bravdo et al. (1984) could attribute the highest 'Carignane' wine quality scores to the lowest Y:PW ratios in 2 of 6 years. Using the combined rankings of sensory attributes, including appearance, aroma, taste, and harmony, Naor et al. (2002) found higher rated 'Sauvignon blanc' wine sensory scores when $\mathrm{Y}: \mathrm{PW}$ decreased and LA:Y increased greater than $1.8 \mathrm{~m}^{2} \cdot \mathrm{kg}^{-1}$.

The influence of yields on sensory perception of wine quality was of less importance than floor management treatments. Both consumers and winemakers considered wine from a Tilled treatment to be in the lowest quality group. Both panels ranked wine from Alternate vines with no cluster thinning to be of higher quality. This is dissimilar to the finding by Filippetti et al. (2013) studying 'Sangiovese' in Tuscany, Italy, where high vigor vines were considered to be of lesser quality than low vigor vines as both Tilled and Alternate vines in our study were considered of high vigor.
Winemakers were able to distinguish Grass-Half Crop wines apart from all other treatments. Although neither panel liked this treatment more than others (in liking test), consumers gave it a higher quality rating (preference test). Reynolds et al. (1996) found greater cherry, berry, and currant aromas in cluster-thinned 'Pinot noir' grown in Oregon, which may be similar to the jammy aroma that was associated with the Grass-Half Crop in our study. These wine sensory differences were found in only 1 year and no differences in any wine sensory tests were found in the other 2 years, including 2011 , the year with the greatest range of yields and most consistent berry component impacts between treatments. This may suggest that sensory perception differences in 2013 were related to other factors than the field treatments employed in that year, such as variation in panelists, small panel size, growing season, etc.

\section{Conclusion}

The floor management and cluster thinning treatments employed in this study resulted in a range of crop loads that helped explore relationships between vine productivity and berry composition at harvest. The relationships were evaluated to understand which factors may be altered by vineyard canopy management practices to reach desired fruit composition and to estimate wine quality. Given the relationships between tissue $\mathrm{N}$ and vine growth measures, $\mathrm{N}$ was likely a physiological driver of source-sink relationships affecting berry composition. Total soluble solids were best explained by crop load, whereas other berry components were better explained by leaf blade $\mathrm{N}$, yield, $P P F$, or a combination of these factors. Winemakers were not able to distinguish between wines of different yields in any year, suggesting that yield management does not ensure wines that can be perceived as having higher sensory quality, despite the strong industry adherence to this paradigm.
Furthermore, viticultural practices other than yield management and annual climate conditions likely had a greater impact on vine growth and fruit composition in this study. In regard to sensory perception, individual panelist taste preferences and experimental wine lacking flavors from wood aging may have influenced wine quality perceptions. These factors together make the use of crop load metrics to achieve even the most basic ripening parameter such as TSS unreliable under the cool climate conditions studied herein. These findings suggest there is an intricate relationship between season and yield which affects berry composition and wine perception, and neither canopy to yield or yield metrics can be universally applied each season.

\section{Literature Cited}

Bravdo, B., Y. Hepner, C. Loinger, S. Cohen, and H. Tabacman. 1984. Effect of crop level on growth, yield and wine quality of a high yielding Carignane vineyard. Amer. J. Enol. Viticult. 35:247-252.

Bravdo, B., Y. Hepner, C. Loinger, S. Cohen, and H. Tabacman. 1985. Effect of crop level and crop load on growth, yield, must and wine composition, and quality of Cabernet Sauvignon. Amer. J. Enol. Viticult. 36:125-131.

Christensen, P., M.L. Bianchi, W.L. Peacock, and D.J. Hirschfelt. 1994. Effect of nitrogen fertilizer timing and rate on inorganic nitrogen status, fruit composition, and yield of grapevines. Amer. J. Enol. Viticult. 45:377-387.

Delgado, R., P. Martín, M. del Álamo, and M-R. González. 2004. Changes in the phenolic composition of grape berries during ripening in relation to vineyard nitrogen and potassium fertilization rates. J. Sci. Food Agr. 84:623630 .

Dokoozlian, N.K. and W.M. Kliewer. 1995. The light environment within grapevine canopies. I. Description and seasonal changes during fruit development. Amer. J. Enol. Viticult. 46:209218.

Dokoozlian, N.K. and W.M. Kliewer. 1996. Influence of light on grape berry growth and composition varies during fruit development. J. Amer. Soc. Hort. Sci. 121:869-874.

Downey, M.O., J.S. Harvey, and S.P. Robinson. 2004. The effect of bunch shading on berry development and flavonoid accumulation in Shiraz grapes. Austral. J. Grape Wine Res. 10:55-73.

Feng, H., F. Yuan, P.A. Skinkis, and M.C. Qian. 2015. Influence of cluster zone leaf removal on Pinot noir grape chemical and volatile composition. Food Chem. 173:414-423.

Filippetti, I., G. Allegro, G. Valentini, C. Pastore, E. Colucci, and C. Intrieri. 2013. Influence of vigour on vine performance and berry composition of cv. Sangiovese (Vitis vinifera L.) J. Intl. Sci. Vigne Vin 47:21-33.

Frioni, T., S. Zhuang, A. Palliotti, P. Sivilotti, R. Falchi, and P. Sabbatini. 2017. Leaf removal and cluster thinning efficiencies are highly modulated by environmental conditions in cool climate viticulture. Amer. J. Enol. Viticult. 68:325-335.

Geller, J.P. and S.K. Kurtural. 2013. Mechanical canopy and crop-load management of Pinot gris in a warm climate. Amer. J. Enol. Viticult. 64:65-73.

Guidoni, S., P. Allara, and A. Schubert. 2002. Effect of cluster thinning on berry skin anthocyanin 
composition of Vitis vinifera cv. Nebbiolo. Amer. J. Enol. Viticult. 53:224-226.

Hannam, K.D., G.H. Neilsen, T. Forge, and D. Neilsen. 2013. The concentration of yeast assimilable nitrogen in Merlot grape juice is increased by $\mathrm{N}$ fertilization and reduced irrigation. Can. J. Plant Sci. 93:37-45.

Howell, G.S. 2001. Sustainable grape productivity and the growth-yield relationship: A review. Amer. J. Enol. Viticult. 52:165-174.

Iland, P.G., W. Cynkar, I.L. Francis, P.J. Williams, and B.G. Coombe. 1996. Optimisation of methods for the determination of total redfree glycosyl glucose in black grape berries of Vitis vinifera. Austral. J. Grape Wine Res. 2:171-178.

International Organization for Standardization. 1977. ISO 3591: Sensory analysis_-ApparatusWine-tasting glass. Geneva, Switzerland.

Jackson, D.I. 1986. Factors affecting soluble solids, acid, pH, and color in grapes. Amer. J. Enol. Viticult. 37:179-183.

Jackson, D.I. and P.B. Lombard. 1993. Environmental and management practices affecting grape composition and wine quality-A review. Amer. J. Enol. Viticult. 44:409-430.

Kaps, M.L. and G.A. Cahoon. 1992. Growth and fruiting of container-grown Seyval blanc grapevines modified by changes in crop level, leaf number and position, and light exposure. Amer. J. Enol. Viticult. 43:191-199.

Keller, M. and G. Hrazdina. 1998. Interaction of nitrogen availability during bloom and light intensity during veraison. II. Effects on anthocyanin and phenolic development during grape ripening. Amer. J. Enol. Viticult. 49:341-349.

Keller, M., L.J. Mills, R.L. Wample, and S.E. Spayd. 2005. Cluster thinning effects on three deficit-irrigated Vitis vinifera cultivars. Amer. J. Enol. Viticult. 56:91-103.

King, P.D., R.E. Smart, and D.J. McClellan. 2015. Timing of crop removal has limited effect on Merlot grape and wine composition. Agr. Sci. 6:456-465.

Kliewer, W.M. 1970. Effect of time and severity of defoliation on growth and composition of 'Thompson Seedless' grapes. Amer. J. Enol. Viticult. 21:37-47.

Kliewer, W.M. and A.J. Antcliff. 1970. Influence of defoliation, leaf darkening, and cluster shading on the growth and composition of Sultana grapes. Amer. J. Enol. Viticult. 21:2636.

Kliewer, W.M. and J.R. Weaver. 1971. Effect of crop level and leaf area on growth, composition, and coloration of 'Tokay' grapes. Amer. J. Enol. Viticult. 22:172-177.

Kliewer, W.M. and N.K. Dokoozlian. 2005. Leaf area/crop weight ratios of grapevines: Influence on fruit composition and wine quality. Amer. J. Enol. Viticult. 56:170-181.

Kliewer, W.M. and T. Casteel. 2003. Canopy management, p. 177-184. In: E. Hellman (ed.). Oregon viticulture. Oregon State Univ. Press, Corvallis, OR.
Koblet, W., M.C. Candolfi-Vasconcelos, W. Zweifel, and G.S. Howell. 1994. Influence of leaf removal, rootstock, and training system on yield and fruit composition of Pinot noir grapevines. Amer. J. Enol. Viticult. 45:181-187.

Lee, J. and P.A. Skinkis. 2013. Oregon 'Pinot noir' grape anthocyanin enhancement by early leaf removal. Food Chem. 139:893-901.

Lee, J. and R.P. Schreiner. 2010. Free amino acid profiles from 'Pinot noir' grapes are influenced by vine $\mathrm{N}$-status and sample preparation method. Food Chem. 119:484-489.

Lee, J., R.W. Durst, and R.E. Wrolstad. 2005. Determination of total monomeric anthocyanin pigment content of fruit juices, beverages, natural colorants, and wines by the $\mathrm{pH}$ differential method: Collaborative study. J. AOAC Intl. 88:1269-1278.

Masuoka, S., D. Hatjopoulos, and M. O'Mahony. 1995. Beer bitterness detection: Testing Thurstonian and sequential sensitivity analysis models for triad and tetrad methods. J. Sens. Stud. 10:295-306.

May, P., N.J. Shaulis, and A.J. Antcliff. 1969. The effect of controlled defoliation in the Sultana vine. Amer. J. Enol. Viticult. 20:237-250.

Morrison, J.C. and A.C. Noble. 1990. The effects of leaf and cluster shading on the composition of Cabernet Sauvignon grapes and on fruit and wine sensory properties. Amer. J. Enol. Viticult. 41:193-200.

Naor, A., Y. Gal, and B. Bravdo. 2002. Shoot and cluster thinning influence vegetative growth, fruit yield, and wine quality of 'Sauvignon blanc' grapevines. J. Amer. Soc. Hort. Sci. 127:628-634.

Neilsen, G.H., D. Neilsen, P. Bowen, C. Bogdanoff, and K. Usher. 2010. Effect of timing, rate, and form of fertilization on nutrition, vigor, yield, and berry yeast-assimilable $\mathrm{N}$ of grape. Amer. J. Enol. Viticult. 61:327-336.

Ough, C.S., L.A. Lider, and J.A. Cook. 1968. Rootstock-scion interactions concerning wine making. I. Juice composition changes and effects on fermentation rate with St. George and 99-R rootstocks at two nitrogen fertilizer levels. Amer. J. Enol. Viticult. 19:213-227.

Price, S.F., P.J. Breen, M. Valladao, and B.T. Watson. 1995. Cluster sun exposure and quercetin in Pinot noir grapes and wine. Amer. J. Enol. Viticult. 46:187-194.

Reeve, A.L., P.A. Skinkis, A.J. Vance, J. Lee, and J.M. Tarara. 2016. Vineyard floor management influences 'Pinot noir' vine growth and productivity more than cluster thinning. HortScience 51:1233-1244.

Reynolds, A.G. and J.E. Vanden Heuvel. 2009. Influence of grapevine training systems on vine growth and fruit composition: A review. Amer. J. Enol. Viticult. 60:251-268.

Reynolds, A.G., R.M. Pool, and L.R. Mattick. 1986. Influence of cluster exposure on fruit composition and wine quality of Seyval blanc grapes. Vitis 25:85-95.
Reynolds, A.G., S.F. Price, D.A. Wardle, and B.T. Watson. 1994. Fruit environment and crop level effects on Pinot noir. I. Vine performance and fruit composition in British Columbia. Amer. J. Enol. Viticult. 45:452-459.

Reynolds, A.G., S. Yerle, B. Watson, S.F. Price, and D.A. Wardle. 1996. Fruit environment and crop level effects on Pinot noir. III. Composition and descriptive analysis of Oregon and British Columbia wines. Amer. J. Enol. Viticult. 47:329-339.

Sarneckis, C.J., R.G. Dambergs, P. Jones, M. Mercurio, M.J. Herderich, and P.A. Smith. 2006. Quantification of condensed tannins by precipitation with methyl cellulose: Development and validation of an optimized tool for grape and wine analysis. Austral. J. Grape Wine Res. 12:39-49.

Schreiner, R.P. and C.F. Scagel. 2017. Leaf blade versus petiole nutrient tests as predictors of nitrogen, phosphorus, and potassium status of 'Pinot noir' grapevines. HortScience 52:174184.

Schreiner, R.P., C.F. Scagel, and J. Lee. 2014. N, P, and $\mathrm{K}$ supply to Pinot noir grapevines: Impact on berry phenolics and free amino acids. Amer. J. Enol. Viticult. 65:43-49.

Schreiner, R.P., J. Lee, and P.A. Skinkis. 2013. $\mathrm{N}$, P, and K supply to Pinot noir grapevines: Impact on vine nutrient status, growth, physiology, and yield. Amer. J. Enol. Viticult. 64:26-38.

Spayd, S.E., J.M. Tarara, D.L. Mee, and J.C. Ferguson. 2002. Separation of sunlight and temperature effects on the composition of Vitis vinifera cv. Merlot berries. Amer. J. Enol. Viticult. 53:171-182.

Spayd, S.E., R.L. Wample, R.G. Evans, R.G. Stevens, B.J. Seymour, and C.W. Nagel. 1994. Nitrogen fertilization of White Riesling grapes in Washington. Must and wine composition. Amer. J. Enol. Viticult. 45:34-42.

Uriarte, D., D.S. Intrigliolo, L.A. Mancha, J. PicónToro, E. Valdes, and M.H. Prieto. 2016. Interactive effects of irrigation and crop level on Tempranillo vines in a semiarid climate. Amer. J. Enol. Viticult. 66:101-111.

Uzes, D.M. and P.A. Skinkis. 2016. Factors influencing yield management of Pinot noir vineyards in Oregon. J. Ext. 54:3. <http://www.joe.org/joe/ 2016june/rb5.php $>$.

Vance, A.J. 2012. Impacts of crop level and vine vigor on vine balance and fruit composition in Oregon Pinot noir. Ore. State Univ., Corvallis, OR, MS Thesis. <http://hdl.handle.net/1957/30290>.

Waterhouse, A.L. 2002. Polyphenolics: Determination of total phenolics, p. 463-470. In: R.E. Wrolstad (ed.). Current protocols in food analytical chemistry. Wiley, Hoboken, NJ.

Zhuang, S., L. Tozzini, A. Green, D. Acimovic, S.G. Howell, S.D. Castellarin, and P. Sabbatini. 2014. Impact of cluster thinning and basal leaf removal on fruit quality of Cabernet franc (Vitis vinifera L.) grapevines grown in cool climate conditions. HortScience 49:750-756. 